\title{
Quality Control throughout the Production Process of Infant Food
}

\author{
Pia Hamrin Birgit Hoeft \\ DSM Nutritional Products Ltd., Kaiseraugst, Switzerland
}

\begin{abstract}
Key Words
Quality control · Infant formula • Infant nutrition •

Food safety $\cdot$ Production process $\cdot$ Prevention
\end{abstract}

\begin{abstract}
The manufacture of infant food is a highly complex process and needs an effective quality control beyond classical inprocess parameters and a final microbiological analysis. To ensure a safe end -product, various tools, such as the Hazard Analysis Critical Control Points (HACCP), have been developed to facilitate the management of food safety. Every single infant formula ingredient must have an excellent quality and safety approach because even if an ingredient is used in very small quantities in a single product, serious consequences may arise if the quality and product safety are not taken seriously by the ingredient manufacturer. The purpose of this article was twofold: firstly, to briefly describe existing Quality Management Systems and, secondly, to highlight the consequences of non-quality.
\end{abstract}

Copyright $\odot 2012$ S. Karger AG, Basel

\section{Introduction}

Infant formulas are the sole or predominant source of nutrition for many infants. Thus, quality control is crucial in the production processes in order to have safe infant food products on the markets. But quality control alone is not enough; manufacturers must embrace quality beyond classical in-process parameters and a final microbiological analysis [1-3]. So, where does quality and safety start? This article attempts to address this question from an industrial point of view.

\section{Quality Management at an Infant Food Ingredient Manufacturer}

In many countries, laws and regulations require food chain stakeholders to have systematic process controls in place and further apply a systematic risk-based approach such as the Hazard Analysis and Critical Control Points (HACCP). The HACCP breaks down the food manufacturing process into logical steps to identify possible physical (e.g., glass), chemical (e.g., allergens), and biological (e.g., Salmonella spp.) hazards for every step in the whole process $[4,5]$. The requirements develop further to encompass integrated approaches like the EU Commission 'Farm to Fork' policy or food defense as in the new US Food Safety Modernization Act [3, 6]. The 'Farm to Fork' policy covers all sectors of the food chain including feed production, primary production, food processing storage, transport, and retail sale. To ensure a systematic implementation of quality-related legal and regulatory requirements, certifications towards well-known standards

\section{KARGER}

Fax +4161306 1234

E-Mail karger@karger.ch

www.karger.com
(C) 2012 S. Karger AG, Basel

0250-6807/12/0603-0208\$38.00/0

Accessible online at:

www.karger.com/anm
Pia Hamrin

Wurmisweg 576, Bld. 241/653

CH-4303 Kaiseraugst (Switzerland)

Tel. +41 6181585 19, E-Mail pia.hamrin@dsm.com 


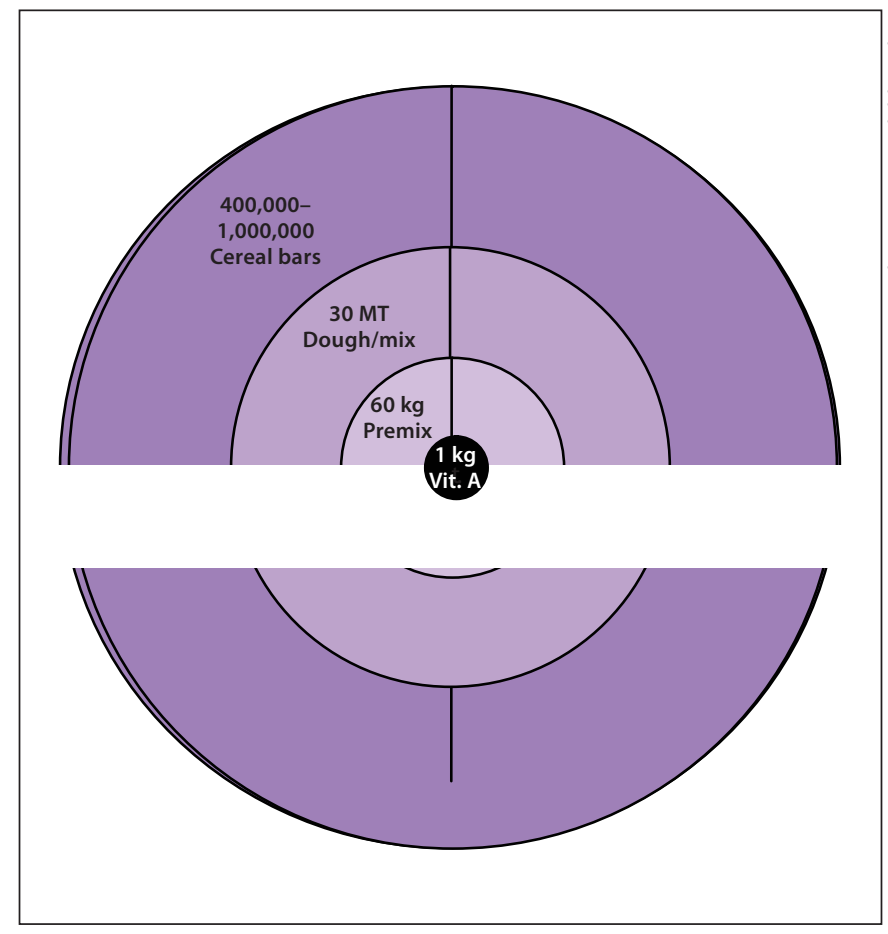

Fig. 1. One kilogram of vitamin A is apportioned to approximately 8 metric tons of infant formula, potentially reaching more than 9,000 babies. Lack of sustainable quality puts the entire value chain at risk.

are useful. The ISO 9001 standard [7] is a generic industry-independent standard that is further derived into different industry-specific standards to facilitate, e.g., food chain companies to comply with the various applicable regulatory and industry-specific requirements.

Other attempts are made by the Global Food Safety Initiative (GFSI), a non-profit initiative launched in 2000 by the Consumer Goods Forum. Current activities within the GFSI include the definition of food safety requirements throughout the food supply chain. The GFSI [8] recognizes selected available standards, e.g., FSSC22000 [9] which combines ISO 22000 [10] and PAS220 [11], after benchmarking them against applicable food safety requirements.

Food-related international standards and requirements for specific types of food like halal and kosher, have besides the general quality requirements a strong focus on prerequisite programs and HACCP programs including hygiene control. Identification of the critical control points and addressing them in a systematic controlled manner ensures both a systematic approach to quality management for the manufacturers themselves and also facilitates follow-ups for authorities during inspections.

The following checkups are relevant for ingredients intended for the food market:

- Zone concept; highly hygienic zone separated by air locks

- HACCP, especially for infant food

- Assurance of homogeneity across the whole batch

- In-process control

- Testing of critical raw materials to meet infant food specifications, e.g., corn starch

- Validated methods for the detection of enterobacteria (including Cronobacter sakazakii) and Bacillus cereus

- Available water activity $<0.6$

- Supplier questionnaires from raw material suppliers completed and accepted

- Environmental monitoring including production, filling, and packaging

\section{Cost of Non-Quality}

Despite international and national legislation, improvements throughout the food chain, and the fact that, compared to all other food categories, today infant products are the most tested, incidents happen. Food safety risks are an international challenge for food manufacturers, governments, and academia, the infant formula crisis in China in 2008 being one recent example. More than 294,000 infants were affected, with 51,900 hospitalizations and at least six deaths [12]. The crisis also had a serious impact on the country's economy, food trade, and even politics [13]. Ingredient manufacturers must have an excellent quality and safety approach because even if an ingredient is used in very small quantities in a single product, serious consequences may arise if the quality and product safety are not taken seriously by the ingredient manufacturer (fig. 1).

\section{Conclusion}

To assure product quality as well as product safety, the ingredient manufacturer's quality management system must be set up so that any issues or deviations can be detected as early as possible and before the finished product reaches the customers. This requires a sound, thought-through approach to quality and safety that allows the manufacturer to work systematically together with the government, other food producers and market- 
ers, academia, and with policy makers and consumers [14]. The longer it takes to detect and solve an issue, the more costs are generated, and the risk for adverse effects increases.

\section{Disclosure Statement}

At the time when the work for this publication was performed both authors were employed at DSM Nutritional Products.

\section{References}

1 USA Code of Federal Regulations:21CFR106, title 21, volume 2, part 106: Infant formula quality control procedures. April 1, 2011.

2 USA Code of Federal Regulations: 21CFR110, title 21, volume 2, part 110: Current good manufacturing practice in manufacturing, packing, or holding human food. April 1, 2011.

3 The European Parliament and the Council of the European Union Commission: Implementing Regulation (EU) 178/2002. Official Journal L 031, 01/02/2002:0001-0024.

4 World Health Organization: HACCP - Introducing the Hazard Analysis and Critical Control Point System. Geneva, 1997.
5 Mortimore SE, Wallace C, Cassianos C: HACCP. Oxford, Blackwell, 2001.

6 USA Public Law: An Act to Amend the Federal Food, Drug, and Cosmetic Act with Respect to the Safety of the Food Supply. 2011, pp 111-353.

7 ISO9001: Quality Management Systems Requirements. 2008.

8 Global Food Safety Initiative: GFSI Guidance Document, ed 6, issue 2, version 6.1. 2011.

9 The Foundation for Food Safety Certification: FSSC22000. www.fssc22000.com.

10 ISO22000: Food Safety Management Systems - Requirements for Any Organization in the Food Chain. 2005.
11 BSI Group (British Standard Institution): BSI PAS 220: Prerequisite Programmes on Food Safety for Food Manufacturing. 2008.

12 Yang R, Wei H, Lishi Z, Miles T, Xiaofang P: Milk adulteration with melamine in China: crisis and response. Quality Assurance and Safety of Crops and Foods 2009;1:111-116.

13 Chen JS: What can we learn from the 2008 melamine crisis in China? Biomed Environ Sci 2009;22:109-111.

14 Lupien JR: Prevention and control of food safety risks: the role of governments, food producers, marketers, and academia. Asia Pac J Clin Nutr 2007;16(suppl 1):74-79. 